\title{
CONSTRUCTIVE THINKING AND TEACHING SELF-EFFICACY OF GREEK SPECIAL EDUCATORS: PARALLEL OR CROSSOVER TOPICS?
}

\author{
Pinelopi Chousou ${ }^{1 \mathrm{i}}$, \\ Thomas Simos², \\ Evdoxia Sakellaropoulou ${ }^{3}$ \\ ${ }^{1}$ Department of Primary Education, \\ University of Ioannina, \\ Greece \\ ${ }^{2}$ Department of Biological Applications and Technologies, \\ University of Ioannina, \\ Greece \\ ${ }^{3}$ Epirus Regional Educational Planning Center, \\ Ministry of Education, \\ Greece
}

\begin{abstract}
:
In the present study we investigated the relationship between Epstein's components of constructive thinking and Teaching Self-Efficacy of Greek special educators. For that purpose, a web questionnaire was sent to special and general education teachers and a research causal model was designed to define relations between variables. The research sample consisted of 214 special educators and general education teachers from the public education system in Greece. Data gathered by utilizing Constructive Thinking Inventory [CTI] and The Teachers' Sense of Efficacy Scale [TSES] research tools. Data analysis revealed a statistically significant correlation of various components of constructive thinking with Teaching Self-Efficacy. In addition, it has been found that a high degree of constructive thinking increases the Teaching Self-Efficacy of special educators. Finally, we compared the teaching self-efficacy between special and general educators.
\end{abstract}

Keywords: constructive thinking, special educator's self-efficacy, teachers' sense of efficacy

\section{Introduction}

The history of Special Education begins in ancient Greece, where the Socratic methodology of education included all individuals, to reach the present day in which the rights of individuals and the responsibilities of those who educate them are defined by

i Correspondence: email pchousou@gmail.com 
law (Curran, 2017). The field of Special Education has evolved significantly over the past half century. First of all, there has been a remarkable turn from home-based education for people with special education needs, to training in specialized schools and integrated support units, and now there is a growing demand for inclusive education (Bronwell et al., 2010; Shepard et al., 2016).

According to the literature review, the majority of studies in Special Education focus on the readiness of general education teachers in order to work in an inclusive environment. In particular, several studies suggested that teachers do not feel well prepared to teach students with different needs. In addition, contact with these students can lead to greater stress, as teachers have to cope with the undeniable complexity of teaching children with disabilities (Forlin \& Chambers, 2011; Hemming \& Woodcock, 2011). Special educators often refer to the need to manage difficult situations in the classes they teach (Bay \& Parker-Katz, 2009) and express their inability to successfully interpret the role assigned to them. Indeed, among their varied tasks, they must teach in several different environments such as typical classrooms, special schools or general education classrooms, and work with different professionals in a variety of teaching forms including co-teaching and teacher assistants. Finally, they must provide appropriate guidance and teaching to students with diverse needs and disabilities, across multiple levels and subjects, academic and non-academic (McCall et al., 2014).

Various theoretical models have been formulated from time to time in order to interpret and illustrate teacher's self-efficacy. Teaching self-efficacy is considered not only as non-static but also dependent on factors such as the school atmosphere, family background, student behavior and most importantly on the role of the teacher in the classroom. Based on these, it can be concluded that teacher self-efficacy is linked to a variety of educational variables such as school structure, students and of course teachers themselves.

\subsection{Constructive thinking}

Constructive thinking is defined as "the degree to which a person's automatically thinking the thinking that occurs without deliberate intention - facilitates solving problems in everyday life at a minimum cost in stress" (Epstein, 1998, p. 26). It is also a way of thinking constructively about the world and its events. So instead of reacting to events, a person chooses to interpret and then respond to them in ways that will support growth and development and minimize friction with the outer world of events. According to Epstein (1994), "Emotions in everyday life are almost invariably produced by the preconscious interpretation of events. People are angry, sad, or frightened, not as a direct result of what objectively occurs but because of how they interpret what happens." Therefore, Constructive thinking is all about making good decisions. This goes back to the process of effective decision-making and knowing how to respond appropriately to circumstances. Viewing situations as challenges rather than threats, seeing the positive side of things but not to an unrealistic degree and considering failures and rejections as unfortunate but not the end of the world, are examples of good constructive thinking (Epstein, 1998). Good constructive 
thinkers hold a set of habitual adaptive thoughts that help them to control their feelings and to sustain an action-oriented approach to coping (Drach-Zahavy \& Somech, 1999). On the other hand, poor constructive thinking examples would be worrying needlessly, dwelling on negative events, overgeneralizing, thinking in extremely categorical ways, and thinking in ways that increase unhappiness without accomplishing anything worthwhile.

Although constructive thinking is significantly related to age, it is not related to education, thus suggesting that it is a function of a person's daily experience and total experiences but not the result of a well-designed and targeted learning process (Park et al., 1997). Similarly, Epstein (Epstein, 1992; Epstein \& Meier, 1989) had already argued that constructive thinking is considered as a behavioral ability, which is different from the school or traditionally defined intelligence. In a study of women in pregnancy, they found that those with higher levels of constructive thinking had the most positive thoughts, the least stress and the least use of medical substances during pregnancy. This is consistent with previous findings regarding the role and correlations of constructive thinking, and it makes clear that its influence is not limited to college students but extends to the general population (Park et al., 1997).

Constructive Thinking is measured by six specific components which are a) Emotional Coping, b) Behavioral Coping, c) Categorical Thinking, d) Personal Superstitious Thinking, e) Esoteric thinking and f) Naïve optimism. The two most important of them are Emotional and Behavioral Coping. Garland (1996) reported that both are bipolar and their score reflect the global constructive thinking. On the other hand, the destructive components are personal superstitious thinking categorical thinking, naïve optimism, and esoteric thinking (Epstein, 1992).

Emotional Coping encloses the ability to deal effectively with the inner world of feeling (Epstein, 1998). Good emotional copers emphasize self-acceptance, absence of negative overgeneralization, non-sensitivity and absence of dwelling (Drach-Zahavy \& Somech, 1999).

Behavioral Coping encompasses the capacity to deal effectively with the outer world of events (Epstein, 1998). Behavioral Coping refers to action-oriented thinking. In other words, Behavioral Coping measures the tendency that people have to think in ways that promote effective action (Garland, 1996).

Categorical Thinking is the tendency to view the world in black and white terms without acknowledging shades of gray (Garland, 1996). Moreover, intolerant and judgmental categorical thinkers tend to classify people as good or bad, "for" or "against" them, "winners or "losers" (Epstein, 1998).

Personal Superstitious Thinking does not refer to traditional superstitions but to personal superstitions. Example of this thinking style is the belief that if something good happens to a person, it will be balanced by something equally bad. The broad predominance of superstitious thinking provides compelling evidence that the human mind does not process information by reason alone (Epstein, 1994). 
Esoteric Thinking refers to the degree that people believe in abnormal or unscientific phenomena (Garland, 1996). It is clear therefore that these beliefs include believing in conventional superstitions (breaking mirror, walking under ladder), good luck charms, astrology, ghost and mind control (Epstein, 1998).

Naïve optimism reflects the degree to which a person is optimistic for no obvious reason (Santos-Ruiz et al., 2012). A naïve optimist person tends to jump to conclusions after a positive outcome, as if a single success guaranteed that things would always work this way (Epstein, 1998).

Additionally, Epstein (1998) mentions that Constructive Thinking is related to success at work, physical health, emotional adaptation, success in personal relationships, and greater satisfaction in life. It is also observed that positively affects subjective wellbeing. A survey by Evers et al. (2005), which concerned the attitudes of secondary education teachers, found that intervention programs that promote constructive thinking contribute to reduction burnout of teachers. It seems fare to state that his finding is consistent with the research of Cooley \& Yovanoff (1996), who argue that it would be extremely useful to include programs about Constructive thinking in the teacher training. This research indicates that self-awareness of the various components of thinking can have a preventative and beneficial effect on the well-being of educators during professional career and life in general. Constructive Thinking, as used here, refers to the interactions of implicit beliefs for emotions and events and their influence on conscious thought and behavior. Thus, the question if constructive thinking is linked to self-efficacy of a person, in particular, to teacher's self-efficacy beliefs arises.

\subsection{Teacher self-efficacy}

Teaching self-efficacy as one of the most significant issues related to education through quantitative and qualitative methods has preoccupied a notable number of researchers for many years (Tzivinikou, 2015). The theoretical framework foundation in this work is Bandura's conception of the self-efficacy construct, which is a central feature in his socialcognitive theory (Bandura, 1977, 1986, 2002). This theory has focused on the interaction of relationships between personal, behavioral and environmental factors across the life span, which makes it one of the more comprehensive theories of human functioning. In 1995, Bandura published the volume entitled Self-efficacy: The Exercise of Control, which presented the theoretical foundations of the theory and the numerous applications of the knowledge to education, health, treatment of clinical problems. Teacher self-efficacy (TSE), or teachers' beliefs in their capabilities to "organize and execute the courses of action required to produce given attainments" (Bandura, 1995), at the present time, has been increasingly considered as one of the central determinants of teachers' thought processes, motivation, affective states and actions (Bandura, 1977, 1986; Tschannen-Moran et al., 1998).

It is acceptable that Teacher self-efficacy (TSE) continues to interest the circles of the educational research community, with the number of relevant articles increasing constantly. The research of Antoniou et al. (2017) reveals that gender does not affect the 
mean of teaching self-efficacy because there is no statistically significant difference. This finding is in line with the findings of studies according to which there is no differentiation of teachers' self-efficacy on the basis of gender (Tschannen-Moran \& Hoy, 2007). Besides these findings, so far mentioned Minghui et al. (2018) found that women special educators in China predominate men regarding their teaching self-efficacy. A study by Lamorey \& Wilcox (2005) points out that experience in education is an important factor that predicts the self-efficacy of a teacher. In this study special educators with more years of experience have also scored higher in teaching self-efficacy.

Our theory is based on the assumption that psychological procedures as Constructive Thinking, may affect Teaching Self-Efficacy. The present research is centrally concerned with identifying profiles of teacher personality. More specifically we examine whether teachers' levels of constructive thinking differ in comparison with the personality profile of special educators, their gender and liability position. Based on the preceding review of theory and relevant evidence, the following prediction is advanced: The relationship between constructive thinking and the Teaching Self-Efficacy would lead to the hypothesis that individuals with poor constructive thinking abilities should have low teacher self-efficacy beliefs and vice versa. In line with this hypothesis, the purpose of this study was to examine the potential relationship between constructive thinking skills and teacher's self-efficacy beliefs by existing neuropsychological instruments.

\section{Research questions}

Taking into consideration the above theoretical assumptions (literature review), the factors defined previously, and the conceptual model adopted, the following research questions arise:

1) What sociodemographic characteristics of special educators play a crucial role in constructive thinking?

2) What are the differences between the constructive thinking and teacher selfefficacy beliefs of special educators and teachers who teach to children without disabilities (general education teachers)?

3) What is the relationship between constructive thinking and special educator's selfefficacy?

\section{Method}

\subsection{Participants}

The research sample was determined through convenience sampling and consisted of 214 teachers from the public education system in Greece. Specifically, 107 were Special Educators, who teach students with disabilities aged 14-19 years and the other 107 were teachers who teach students without disabilities (general education teachers) who were between 12 and 18 years of age. Special Educators comprise a representative sample of 
special educators in Greece. Teachers were initially contacted by email and informed of the nature of the study, and after which they were asked to provide written consent for their participation.

Concerning their demographic characteristics, $73.8 \%$ of the participants were female and $26.2 \%$ were male. According to the information obtained from the survey, the age of $63.55 \%$ of special educators was up to 45 years old and the majority of them $(87.85 \%)$ held degrees in special education. Furthermore, $89.82 \%$ of the special educators had less than 15 years teaching experience and $23.36 \%$ was school administrators. In contrary $29.0 \%$ of general education teachers participated, aged from 36 to 45, while $70.1 \%$ were in the age of 46 and over. Moreover $49.5 \%$ of general education teachers do not hold any additional degree while $72 \%$ of them do not have additional degree in special education. On the other hand, general education teachers are more experienced with the $62.7 \%$ of them reporting that they have been working in education for over 15 years.

\subsection{Research tools}

The personal information form was developed by the researchers to determine the teachers' sociodemographic information such as their ages, gender and their studies in special education themes. Also, in personal information form, teachers were asked if they are school administrator and years of experience in special educational schools.

In order to collect the research data Constructive Thinking Inventory Short version (CTI Short) developed by Epstein (1989) was used. The CTI is a 30-item self-report instrument that contains items describing common automatic constructive and destructive ways of thinking. The participants are asked to rate on a five-point Likerttype scale the frequency these automatic constructive and destructive thoughts occur in their everyday life. (e.g. "I feel that if people treat you badly, you should treat them in kind", "I don't take things personally"). It is noted that the items were scored on a five-point scale, ranging from seldom to often. CTI provides a global measure of constructive thinking and includes six subscales (Emotional coping, Behavioral coping, Personal superstitious thinking, Categorical thinking, Esoteric thinking, and Naive optimism) (Rey et al., 2009). This test has been adapted and validated for use in the Greek population by Stalikas \& Roussi (2016). The Emotional and Behavioral coping subscales are keyed so that higher scores indicate greater constructive thinking whereas the other five subscales are keyed so that higher scores indicate more maladaptive or destructive thinking. In our sample Cronbach's alpha reliability for CTI was 0.88 .

Teacher self-efficacy was measured using the long-form of the Teachers' Sense of Self-Efficacy Scale (TSES) (Tschannen-Moran \& Hoy, 2001). Tschannen-Moran \& Hoy (2001) developed this Likert-type scale, to determine the teacher self-efficacy beliefs with 5 -points to rate from on each statement. The TSES comprises a 24 item scale, ranging from 1 (Nothing) to 5 (A great deal). In our sample, coefficient alpha reliability was 0.90 .

The scales were adapted to the Greek context following the international guidelines for cross cultural research and adaptation of behavioral measures. 


\subsection{Procedure}

Our research conducted in the school year 2020-2021 in several special and general schools of secondary education. Initially, e-mails and phones of special schools gathered from the website of the Greek Ministry of Education. After that school unit principals were informed either by e-mail, by telephone or by interpersonal communication about the content of the research. The survey instruments, consent forms, and web questionnaires were sent to the 130 special schools. These materials were distributed to all the teachers of students with disabilities by each school's principal supervising special education. The teachers who voluntarily consented to participate in the study were asked to complete the questionnaire which took approximately 15 minutes. The completed surveys were then collected by the researcher by e-mail. The same procedure was followed in order to collect the questionnaires from general education schools.

\subsection{Statistical analysis}

The Statistical Package for the Social Sciences (SPSS, Version 22) was used for data analysis. To describe constructive thinking, descriptive analysis, of variance (ANOVA,) was performed. The ANOVA was used to compare the effect of differences in personal and professional demographic data. Pearson's product moment correlation was used to examine the relationship of constructive thinking coping styles to teacher self-efficacy beliefs. Furthermore, in order to test which constructive thinking variables best explain scores obtained from TSES questionnaire, we performed multiple regression analysis. The level of significance $p$ of the control was set at value 0.05 . Statistical control values that correspond to the significance level $\mathrm{p}$ are called critical values and determine whether there is a difference or not between the variables. Significance level $p$ below the critical values defines a statistically significant difference between the variables. In particular, the smaller the critical value, the more statistically significant difference is indicated.

Finally, to determine the type of the distribution of the population from which the random sample originated Shapiro-Wilk statistical test was applied. Based on the results of the test, the random sample had a normal distribution.

\section{Results}

\subsection{Constructive thinking and Teaching Self-efficacy scale of special educators}

Means and standard deviations scores for each of the study variables are shown in Table 1. The means of global constructive thinking scores $93.45(\mathrm{sd}=12.206)$, while the means of Teaching Self-Efficacy reaches $97.06(\mathrm{sd}=12.435)$. Both means are based to a large extent on the fact that the rating of constructive thinking is from 30 to 150 and the rating of teaching self-efficacy takes values from 24 to 120 . 
Table 1: Means and standard deviations for the constructive thinking inventory scales and Teaching Self-Efficacy Scale

\begin{tabular}{|l|c|c|}
\hline & Mean $\mathbf{( m )}$ & Standard Deviation (sd) \\
\hline Emotional coping & 14.46 & 3.476 \\
\hline Behavioral coping & 19.35 & 3.500 \\
\hline Categorical thinking & 11.28 & 3.618 \\
\hline Personal superstitious thinking & 10.78 & 4.228 \\
\hline Esoteric thinking & 9.30 & 3.792 \\
\hline Naïve optimism & 17.88 & 3.293 \\
\hline Global constructive thinking & 93.45 & 12.206 \\
\hline Teaching self-efficacy & 97.06 & 12.435 \\
\hline
\end{tabular}

\subsection{Constructive thinking, gender, education, and liability position}

Regarding the relation between Constructive thinking and gender, statistical analysis utilizing ANOVA revealed no significant differences in 6 of the 7 components of constructive thinking. More specifically, differences in Emotional coping $(p=0.341>0.05)$, Behavioral coping $(p=0.322>0.05)$, Categorical thinking $(p=0 . n 094>0.05)$, Personal superstitious thinking $(\mathrm{p}=0.818>0.05)$, Na1ve optimism $(\mathrm{p}=0.051>0.05)$, and Global constructive thinking ( $\mathrm{p}=0.658>0.05)$ between men and women special educators were not statistically significant. Only in the case of Esoteric thinking the results indicated a statistically significant difference $\left(F_{(1.105)}=5.110, \mathrm{p}=0.026<0.05\right)$ with men scoring significantly lower than women.

Moreover, statistical analysis using One-way ANOVA among special educators with different education levels revealed differences in two components of constructive thinking. In particular, the results show a statistically significant difference in Categorical thinking $\left(\mathrm{F}_{(4.102)}=2.681, \mathrm{p}=0.036<0.05\right)$ and Global constructive thinking $\left(\mathrm{F}_{(4.102)}=2.549\right.$, $\mathrm{p}$ $=0.044<0.05)$. Further analysis utilizing the Bonferroni test has shown that Categorical thinking of special educators who have a postgraduate degree in special education areas differ from those with a Bachelor's degree $(p=0.030<0.05)$.

Also, Global constructive thinking of special educators with a postgraduate degree in special education fields differ from those with no studies in special education at all ( $\mathrm{p}$ $=0.035<0.05$ ).

The results show that special educators who hold a position of responsibility (Special school principals) have a higher Behavioral coping and Global constructive thinking than the special educators who do not have any responsibility position. These results are statistically significant, $\left(\mathrm{F}_{(1.105)}=8.162, \mathrm{p}=0.005<0.05\right)$ and $\left(\mathrm{F}_{(1.105)}=4.781, \mathrm{p}=\right.$ $0.031<0.05)$ respectively. More specifically, it was found that Special school administrators performed a high Behavioral coping $(\mathrm{m}=21.04, \mathrm{Sd}=2.806)$ and very high Global constructive thinking $(\mathrm{m}=98.04, \mathrm{Sd}=10.470)$.

\subsection{Comparison of constructive thinking and Teaching Self-efficacy scale of special educators and general education teachers}

A major focus of this study was to examine whether special educators and general education teachers have the same levels of constructive thinking. Statistical analysis 
revealed that special educators have significantly greater Behavioral coping $(p=0.034)$, $(\mathrm{m}=19.35, \mathrm{SD}=3.500)$ than general education teachers $(\mathrm{m}=19.3, \mathrm{SD}=3.226)$. Furthermore, special educators have statistically significant $(\mathrm{p}=0.009)$ greater Navve optimism $(\mathrm{m}=$ $17.88, \mathrm{SD}=3.293)$ than general education teachers $(\mathrm{m}=16.71, \mathrm{SD}=3.216)$. There is no statistically significant difference in the other components of constructive thinking.

In order to determine whether teacher self-efficacy beliefs of special and general education teachers were different, we compared their means. The means of the Teaching Self-Efficacy scale for general education teachers was $m=87.64$ while for the special educators were $m=97.06$. One-way ANOVA revealed that there is statistically significant difference among them $(\mathrm{p}=0.000<\alpha=0.05)$.

\subsection{Correlation between the components of constructive thinking and Teaching Self- efficacy scale}

Global constructive thinking has a relatively strong positive relation with Teaching SelfEfficacy Scale, $r=0.310, p=0.001$ as illustrated in Table 2. This means that if constructive thinking is high, special educator's self-efficacy beliefs will be also high. It is also evident that Emotional coping and Behavioral coping are positive correlated to Teaching SelfEfficacy, $(\mathrm{r}=0.277, \mathrm{p}=0.004)$ and $(\mathrm{r}=0.480, \mathrm{p}=0.000)$. This indicates that people who deal with negative feelings effectively and have action oriented thinking, have also high selfefficacy beliefs. Modest reliability-adjusted correlations existed between Naïve optimism and Teaching Self-Efficacy $(r=0.193, p=0.047)$.

In this study, regression analysis was employed to determine whether constructive thinking and its components were valid predictors of teacher's shelf-efficacy outcomes scores. As the focus of the study is on special education teachers, data from general educators were excluded from the regression analysis. Results revealed that Behavioral coping was the only variable with explanatory predictive value. The other components of constructive thinking are not a significant predictor of teachers' SelfEfficacy.

Table 2: Correlation coefficient between the components of constructive thinking and Teaching Self-Efficacy scale

\begin{tabular}{|l|c|c|}
\hline Correlations & \multicolumn{2}{|c|}{ Teaching Self-efficacy } \\
\hline \multirow{2}{*}{ Emotional coping } & Pearson Correlation & $0.277^{\mathrm{a}}$ \\
\hline \multirow{2}{*}{ Behavioral coping } & Sig. (2-tailed) & $\mathbf{0 . 0 0 4}$ \\
\hline \multirow{2}{*}{ Categorical thinking } & Pearson Correlation & $0.480^{\mathrm{a}}$ \\
\hline \multirow{2}{*}{ Personal superstitious thinking } & Sig. (2-tailed) & $\mathbf{0 . 0 0 0}$ \\
\hline \multirow{2}{*}{ Esoteric thinking } & Pearson Correlation & -0.125 \\
\cline { 2 - 3 } & Sig. (2-tailed) & 0.198 \\
\hline \multirow{2}{*}{ Naïve optimism } & Pearson Correlation & -0.176 \\
\cline { 2 - 3 } & Sig. (2-tailed) & 0.070 \\
\cline { 2 - 3 } & Pearson Correlation & 0.015 \\
\cline { 2 - 3 } & Sig. (2-tailed) & 0.876 \\
\cline { 2 - 3 } & Pearson Correlation & $0.193^{\mathrm{b}}$ \\
\hline
\end{tabular}




\begin{tabular}{|l|c|c|}
\hline \hline \multirow{2}{*}{ Global constructive thinking } & Pearson Correlation & $0.310^{\mathrm{a}}$ \\
\cline { 2 - 3 } & Sig. (2-tailed) & $\mathbf{0 . 0 0 1}$ \\
\hline
\end{tabular}

Note: a. Correlation is significant at the 0.01 level (2-tailed), b. Correlation is significant at the 0.05 level (2tailed).

This means that research question 3 is only valid for one dimension of constructive thinking. This relationship seems to be positive, and the variable Behavioral coping is a significant predictor of teachers' Self-Efficacy (beta $=4.735, \mathrm{p}=0.003$ ) as depicted in Table 3. The fact that the coefficient $B$ of the behavioral response is greater than one $(b=4.735)$ means that a change in the degree of the behavioral coping results in a greater change on the degree of teachers' Self-Efficacy.

Furthermore, a significant model emerged $(p<0.05$ ) explaining 24.9\% (Adj R2) of the variance. In other words, the results show that the effects of Behavioral coping explain over $24.9 \%$ of variance in teachers' Self-Efficacy.

Table 3: Results of the regression analysis for the predicting variables on teachers' shelf-efficacy

\begin{tabular}{|c|c|c|c|c|c|c|}
\hline \multicolumn{7}{|c|}{ Coefficients } \\
\hline \multirow{2}{*}{\multicolumn{2}{|c|}{ Model }} & \multicolumn{2}{|c|}{$\begin{array}{l}\text { Unstandardized } \\
\text { Coefficients }\end{array}$} & \multirow{2}{*}{$\begin{array}{c}\text { Standardized } \\
\text { Coefficients } \\
\text { Beta }\end{array}$} & \multirow[t]{2}{*}{$t$} & \multirow[t]{2}{*}{$\begin{array}{c}\mathrm{p}- \\
\text { value }\end{array}$} \\
\hline & & B & Std. Error & & & \\
\hline \multirow[t]{8}{*}{1} & (Constant) & 109.066 & 12.097 & & 9.016 & 0.000 \\
\hline & Emotional coping & 0.704 & 1.666 & 0.047 & 0.423 & 0.673 \\
\hline & Behavioral coping & 4.735 & 1.581 & 0.349 & 2.995 & 0.003 \\
\hline & Categorical thinking & 0.369 & 1.802 & 0.025 & 0.205 & 0.838 \\
\hline & Personal superstitious thinking & 3.425 & 1.946 & 0.243 & 1.760 & 0.081 \\
\hline & Esoteric thinking & -0.465 & 1.560 & -0.037 & -0.298 & 0.766 \\
\hline & Naïve optimism & -3.206 & 1.722 & -0.197 & -1.862 & 0.066 \\
\hline & Global constructive thinking & 0.562 & 2.487 & 0.045 & 0.226 & .822 \\
\hline
\end{tabular}

Note: Dependent Variable: Teaching Self-Efficacy Scale

\section{Discussion}

The purpose of this study was to examine the relation between constructive thinking and its various components and teachers' Self-Efficacy, as these two broad concepts might be functionally related and their association has not been previously investigated. Constructive thinking is a measure of personality that reflects the ability of an individual to successfully adapt to different aspects of a given situation. As such, constructive thinking could be related to the notion of special educator's self-efficacy beliefs.

Statistical analysis revealed that in both categories female teachers were numerically superior to the males. Regarding their age, there is a difference between special educators who seem to be younger than general educators. More specifically, general education teachers are over 35 years of age, while $27 \%$ of special educators are up to 35 years old. This finding is consistent with the research of Antoniou et al. conducted in 2017 among 200 special educators in Greece, from which it emerged that 
the majority of them are young with an average age of 25.1 years. Perhaps this reflects the interest that has arisen in recent years for the profession of the special educator as opposed to earlier.

Based on the demographic results, most of the general education teachers do not have studies in special education and almost half of them do not have any additional degrees. On the contrary, most of the special educators hold additional degrees, mainly postgraduate or a second degree. However, it is worth noting that out of the 107 special educators, we found that 13 teachers working in secondary special education structures do not hold a degree or have training in special education. This can be interpreted as a need for more special educators. Also, remarkable is the large discrepancy in the occupation of special and general education teachers. More specifically, in special schools fewer than half have permanent teaching positions $(41,12 \%)$, while on the other hand almost all general education teachers have permanent teaching positions (95,33\%). It is clear therefore that these findings reflect the position of special educators in the Greek reality, which is more or less to be expected if we take into account that they are the youngest educators.

One of the aims of this study was to assess the Constructive thinking of special education teachers, who worked with handicapped teenagers in public Greek special schools, in order to understand which variables may affect it.

It was also examined whether the constructive thinking of special educators and general education teachers differ. In particular, the study of these two parameters revealed a statistically significant difference between the degrees of their constructive thinking. Concerning the components of constructive thinking, it was observed a statistically significant difference in behavioral coping. More specifically, it was found that special educators score higher in the behavioral coping component than general education teachers. A potential explanation of these findings may be related to the different characteristics between the samples of special and general education teachers in Greece (e.g. age, permanent position). According to Epstein (1998) good behavioral copers are more accepting of others, more optimistic and more action oriented than other people. Furthermore, good behavioral copers accept people as they are and focus their energy on carrying out their plans. Adaptable curricular materials, alternative activities as well as an increased participation for students are necessary. Instructional planning has to be flexible and geared towards students' needs. All of the above mentioned, require excellent organizational and problem-solving skills, as well as human skills. All these abilities characterize a good behavioral coper.

Interestingly, special educators gave higher scores in teacher's self-efficacy than their colleagues in general education and statistical analysis showed that this difference was not by chance. The demanding and challenging situations, including behavior management, curriculum development, communication/collaboration, identified in special education classes and the different experiences of special educators, who face students with various disabilities, may have strengthen their belief that they are more capable_than general education teachers. What is more, special educators in Greece and 
other countries are responsible for creating a flexible program and learning environment that provides specialized instruction for students with disabilities. As a matter of fact, special educators have direct contact with their pupils and know the result of their teaching and students' educational outcomes. This may contribute to the increase of teacher's self-efficacy beliefs.

This is the first study designed to determine whether there is a relationship between constructive thinking and teacher's self-efficacy. A significant relationship was observed between the Emotional Coping, scale and scores on Teachers self-efficacy (TSES), such that increasing scores on the Emotional Coping scale were associated with increasing special educator self-efficacy beliefs about teaching. This association suggests that individuals with high levels of Emotional Coping can face potentially stressful situations as challenges rather than threats, therefore experiencing less stress under those conditions (Epstein, 2001). It is true that this type of constructive thinking is required for appropriate decision making in our daily lives, and it also appears to be reflected in optimal performance in decision making tasks (Santos-Ruiz at al., 2012). Special educators with high levels of self-efficacy believe that their personal and technical skills as instructors can bring about positive outcomes in the performance of their students and can even overcome the effects of possibly negative environmental influences (Bandura, 1994).

Our data also show a positive relationship between Behavioral Coping, which is the subscale closest to the global scale of constructive thinking, and special educator's self-efficacy. According to Epstein (1998), special educators who have been rated with high scores in Behavioral Coping are characterized by positive feelings and optimism. They circumvent obstacles and compensate quickly for setbacks so as to regain momentum and control. Special educators are confronted with many classroom situations that require quick and competent reactions.

As anticipated, the most powerful predictor of special educator's self-efficacy was the Behavioral Coping. As teaching is an interactive and interpersonal process, special educators with a positive self-oriented cognitive and thinking style will probably interpret classroom problems and difficult student behavior as solvable problems they can cope with, and which will therefore reinforce their positive beliefs about teaching self-efficacy. The results of the present study support the basic assumption that the way of thinking applied by individuals will have an influence on special educator's selfefficacy. "Thinking styles are of great influence on the individual's approach to people, problems, events and circumstances, in short to surrounding world" (Evers et al., 2005).

Despite the fact that literature is poor concerning the relation between Constructive Thinking and the perception of self-efficacy, the current research reveals that Constructive Thinking is a key factor which contributes to the development of the perception of educators' self-efficacy. 


\section{Conclusions and Limitations}

As mentioned, in our research we used self-report instruments. Self-report questionnaires main disadvantage might be the possibility of providing invalid answers. While responding to the items, teachers may not answer truthfully, especially on sensitive questions. This phenomenon is known as social desirability bias, in that they may respond in a socially acceptable way (Bryman, 2017, p.261). Interpreting the differences among the two groups of teachers, it was generally implied that different levels of teacher self-efficacy of the two groups reflected levels of teacher self-efficacy at different stages of their teaching career.

Despite limitations, this study contributes to the literature by demonstrating that Constructive Thinking not only helps to explain the impact of teacher's beliefs but is a powerful predictor in its own right. Although Constructive Thinking cannot be reduced to its subcomponents on scales, the abilities to cope effectively with the outer world (i.e. behavioral coping) and to maintain unrealistic optimism appears to be important components of CT's effect on Teachers self-efficacy. Our findings indicate that personality has strong effect only on special educator's self-efficacy beliefs and also suggest that intervention programs promoting constructive thinking may be successful in increasing teacher's self-efficacy beliefs. Furthermore, our work suggests focusing on special educator's self-efficacy in the framework of the "existential vacuum", which places the study of the teacher's self-efficacy non in a broader perspective of the individual's total personality. However, as the results of the present study are obtained from cross-sectional examinations, we recommend further research on the subject of teacher self-efficacy in the framework of thinking styles.

Finally, it would be even a better idea to include courses on thinking processes in training programs for teachers, for self-knowledge on the various components of thinking may have a preventive and beneficial effect on the teacher's self-efficacy during his or her career. Of course, long-standing forms of perception, thinking, and behavior can be difficult to change. Nevertheless, our results suggest that a focus on Constructive Thinking in counseling could help special educators to increase teaching self-efficacy.

\section{Ethics statement}

All respondents have anonymity and confidentiality. The principals of Special and General Education Schools emailed the survey to the teachers. We did not have access to email addresses, names, or any identifying information of the participants. Individual data results and survey responses will not be shared. The published dissertation is available to view.

\section{Conflict of interest Statement}

The authors declare no conflicts of interests. 


\begin{abstract}
About the Authors
Pinelopi Chousou was born in Arta, Greece, in 1980. She received the B.E. degree in Physics and the M.Tech. degree in New Technologies and the Research in Physics Education from the Department of Physics, University of Ioannina, Greece, in 2009 and 2011, respectively. In 2019, she received her second M.Tech. degree in Special Education from the Department of Primary Education, University of Ioannina, Greece. Since 2019 she is studying at the Department of Primary Education, University of Ioannina, Greece for her second B.E. degree. At the school year 2020-2021 worked as special educator on a program of students' parallel support in public high schools.
\end{abstract}

Thomas Simos was born in Arta, Greece, in 1982. He received the B.E. degree in floriculture and landscape designing from the Technological Educational Institute of Epirus, Arta, Greece, in 2005, and the M.Tech. degree in biological cultivation from the Department of Chemistry, University of Ioannina, Greece, in 2009. In 2009, he joined the Department of Biological Applications and Technology, University of Ioannina, as a Ph.D. candidate in Bioinformatics. He has participated in research programs of the University of Ioannina and has publications in foreign scientific journals and conferences. Dr. Evdoxia Sakellaropoulou is Coordinator of Education at the Epirus Regional Educational Planning Center of the Ministry of Education and a member of the Upper Regional Education Council of Epirus, as well as Regional Council of Choosing School Managers. She has obtained her B.A. in Pedagogy and Theology at the University of Athens. After that she obtained her Doctorate in Education at the University of Ioannina. She has participated in the Ministry of Education research programs and other educational training programs and conferences as a trained, rapporteur or member of the Organizational and Scientific Committee. She participated as a workshop coordinator of the Institute of Educational Policy in relation to the creation of educational material for refugee pupils. She has publications in Greek and foreign scientific journals and has written out scientific textbooks. Her research interests include the following fields: Intercultural Education Pedagogy and Didactic as well as Special Education Pedagogy and Didactic, inclusion of people with cultural and linguistic diversity and people with disabilities, training of education teachers and parents.

\title{
References
}

Antoniou, A., S., Geralexis, I., \& Charitaki, G. (2017). Special educators' teaching selfefficacy determination: A quantitative approach. Psychology, 8(11), 1642-1656. https://doi.org/10.4236/psych.2017.811108

Bandura, A. (1977). Self-efficacy: Toward a unifying theory of behavioral change. Psychological Review, 84(2), 191-215. http://dx.doi.org/10.1037/0033-295X.84.2.191

Bandura, A. (1986). Social foundations of thought and action: A social cognitive theory. Prentice-Hall. 
Bandura, A. (1994). Self-efficacy. In V. S. Ramachaudran (Ed.), Encyclopedia of human behavior (Vol. 4, pp. 71-81). Academic Press. (Reprinted in H. Friedman [Ed.], Encyclopedia of mental health. Academic Press, 1998).

Bandura, A. (1995). Self-efficacy in changing societies. Cambridge University Press.

Bandura, A. (2002). Social cognitive theory in cultural context. Journal of Applied Psychology: An International Review, 51(2), 269-290. https://doi.org/10.1111/1464$\underline{0597.00092}$

Bay, M., \& Parker-Katz, M. (2009). Perspectives on induction of beginning special educators. Teacher Education and Special Education, 32(1), 17-32. https://doi.org/10.1177/0888406408330871

Brownell, T. M., Sindelar, T. P., Kiely, T. M., \& Danielson, L. C. (2010). Special education teacher quality and preparation: Exposing foundations, constructing a new model. Exceptional Children, 76(3), 357-377. https://doi.org/10.1177/001440291007600307

Bryman, A. (2017). Methods of social research. Gutenberg Publications.

Cooley, E., \& Yovanoff, P. (1996). Supporting professionals-at-risk: Evaluating interventions to reduce burnout and to improve retention of special educators. Exceptional Children, 62(4), 336-355. https://doi.org/10.1177/001440299606200404

Curran, A. (2017). Burnout: Special education teachers experiences with career demands. [Unpublished doctoral dissertation]. Boston University.

Drach-Zahavy, A., \& Somech, A. (1999). Constructive thinking: A complex coping variable that distinctively influences the effectiveness of specific difficult goals. Personality and Individual Differences, 27(5), 969-984. http://dx.doi.org/10.1016/S0191-8869(99)00041-0

Epstein, S., \& Meier, P. (1989). Constructive thinking: A broad coping variable with specific components. Journal of Personality and Social Psychology, 57(2), 332-350. http://dx.doi.org/10.1037/0022-3514.57.2.332

Epstein, S. (1992). Coping ability, negative self-evaluation, and overgeneralization: Experiment and theory. Journal of Personality and Social Psychology, 62(5), 826-836. http://dx.doi.org/10.1037/0022-3514.62.5.826

Epstein, S. (1994). Integration of the cognitive and the psychodynamic unconscious. American Psychologist, 49(8), 709-724. https://doi.org/10.1037/0003-066X.49.8.709

Epstein, S. (1998). Constructive thinking. The key of emotional intelligence. Paeger Publishers.

Evers, W., Tomic, W., \& Brouwers, A. (2005). Constructive thinking and burnout among secondary school teachers. Social Psychology of Education 8(4), 425-439. https://doi.org/10.1007/s11218-005-0663-8

Forlin, C., \& Chambers, J. C. (2011). Teacher preparation for inclusive education: Increasing knowledge but raising concerns. Asia-Pacific Journal of Teacher Education, 39(1), 17-32. http://dx.doi.org/10.1080/1359866X.2010.540850

Garland, I. D. (1996). Practical thinking, academic average, and the relationship to the constructive thinking inventory. [Unpublished doctoral dissertation]. Mount Saint Vincent University. 
Hemmings, B. C., \& Woodcock, S. (2011). Preservice teachers' views of inclusive education: A content analysis. Australasian Journal of Special Education, 35(2), 103116. https://doi.org/10.1375/ajse.35.2.103

Lamorey, S., \& Wilcox, M. (2005). Early intervention practitioners' self-efficacy: A measure and its applications. Early Childhood Research Quarterly, 20(1), 69-84. https://doi.org/10.1016/j.ecresq.2005.01.003

McCall, Z., McHatton, P. A., \& Shealey, M. W. (2014). Special education teacher candidate assessment: A review. Teacher Education and Special Education, 37(1), 51-70. https://doi.org/10.1177/0888406413512684

Minghui, L., Lei, H., Xiaomeng, C., \& Potmešilc, M. (2018). Teacher efficacy, work engagement, and social support among Chinese special education school teachers. Frontiers in Psychology, 9(7), 648. https://doi.org/10.3389/fpsyg.2018.00648

Park, C. L., Moore, P. J., Turner, R. A., \& Adler, N. E. (1997). The roles of constructive thinking and optimism in psychological and behavioral adjustment during pregnancy. Journal of Personality and Social Psychology, 73(3), 584-592. http://dx.doi.org/10.1037/0022-3514.73.3.584

Rey, E., Ortega, M. M., Garcia Alonso, M. O., \& Diaz-Rubio, M. (2009). Constructive thinking, rational intelligence and irritable bowel syndrome. World Journal of Gastroenterology, 15(25), 3106-3113. https://dx.doi.org/10.3748/wjg.15.3106

Santos-Ruiz, A., Fernandez-Serrano, M. J., Robles-Ortega, H., Perez-Garcia, M., Navarrete-Navarrete, N., \& Peralta-Ramirez, M.I. (2012). Can constructive thinking predict decision making? Journal of Behavioral Decision Making, 25(5), 469475. https://doi.org/10.1002/bdm.747

Shepard, K. G., Fowler, S., McCormick, J., Wilson, C. L., \& Morgan, D. (2016). The search for role clarity: Challenges and implications for special education teacher preparation. Teacher Education and Special Education, 39(2), 83-97. https://doi.org/10.1177/0888406416637904

Stalikas, A., \& Roussy, P. (2016). Psychometric tools in Greece. Ellinika Grammata.

Tschannen-Moran, M., \& Hoy, A.W. (2001). Teacher efficacy: Capturing an elusive

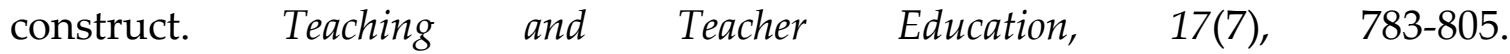
http://dx.doi.org/10.1016/S0742-051X(01)00036-1

Tschannen-Moran, M., \& Hoy, A. W. (2007). The differential antecedents of self-efficacy beliefs of novice and experienced teachers. Teaching and Teacher Education, 23(6), 944-956. http://dx.doi.org/10.1016/j.tate.2006.05.003

Tschannen-Moran, M., Hoy, A. W. \& Hoy, W. K. (1998). Teacher efficacy: Its meaning and measure. Review of Educational Research, 68(2), 202-248. https://doi.org/10.3102/00346543068002202

Tzivinikou, S. (2015). Collaboration between General and Special Education Teachers: Developing Co-teaching Skills in Heterogeneous Classes. Problems of education in the 21st century, 64, 108-119. 
Pinelopi Chousou, Thomas Simos, Evdoxia Sakellaropoulou

CONSTRUCTIVE THINKING AND TEACHING SELF-EFFICACY OF

GREEK SPECIAL EDUCATORS: PARALLEL OR CROSSOVER TOPICS?

Creative Commons licensing terms

Authors will retain the copyright of their published articles agreeing that a Creative Commons Attribution 4.0 International License (CC BY 4.0) terms will be applied to their work. Under the terms of this license, no permission is required from the author(s) or publisher for members of the community to copy, distribute, transmit or adapt the article content, providing a proper, prominent and unambiguous attribution to the authors in a manner that makes clear that the materials are being reused under permission of a Creative Commons License. Views, opinions and conclusions expressed in this research article are views, opinions and conclusions of the author(s). Open Access Publishing Group and European Journal of Special Education Research shall not be responsible or answerable for any loss, damage or liability caused in relation to/arising out of conflict of interests, copyright violations and inappropriate or inaccurate use of any kind content related or integrated on the research work. All the published works are meeting the Open Access Publishing requirements and can be freely accessed, shared, modified, distributed and used in educational, commercial and non-commercial purposes under a Creative Commons Attribution 4.0 International License (CC BY 4.0). 